\title{
Review Article \\ Recent Development of Nanocomposite Membranes for Vanadium Redox Flow Batteries
}

\author{
Sang-Ho Cha \\ Department of Chemical Engineering, Kyonggi University, 154-42 Gwanggyosan-ro, Yeongtong-gu, Suwon 443-760, Republic of Korea
}

Correspondence should be addressed to Sang-Ho Cha; sanghocha@kgu.ac.kr

Received 19 June 2015; Accepted 2 August 2015

Academic Editor: Jin Yang

Copyright (C) 2015 Sang-Ho Cha. This is an open access article distributed under the Creative Commons Attribution License, which permits unrestricted use, distribution, and reproduction in any medium, provided the original work is properly cited.

The vanadium redox flow battery (VRB) has received considerable attention due to its long cycle life, flexible design, fast response time, deep-discharge capability, and low pollution emissions in large-scale energy storage. The key component of VRB is an ion exchange membrane that prevents cross mixing of the positive and negative electrolytes by separating two electrolyte solutions, while allowing the conduction of ions. This review summarizes efforts in developing nanocomposite membranes with reduced vanadium ion permeability and improved proton conductivity in order to achieve high performance and long life of VRB systems. Moreover, functionalized nanocomposite membranes will be reviewed for the development of next-generation materials to further improve the performance of VRB, focusing on their properties and performance of VRB.

\section{Introduction}

As one kind of energy storage systems, vanadium redox flow battery (VRB) is the most promising technology due to several advantages such as its high storage capacity, moderate operating temperature, and long cycle life [1-11]. A VRB is an electrochemical system storing electric energy in chemical energy, which consists of two electrolyte tanks equipped with $\mathrm{V}(\mathrm{II}) / \mathrm{V}(\mathrm{III})$ and $\mathrm{V}(\mathrm{IV}) / \mathrm{V}(\mathrm{V})$ redox couples in sulfuric acid solution, two pumps, two electrodes, and a battery stack section with ion exchange membranes (Figure 1). To store and release energy, two separate electrolyte solutions undergo redox reaction in the respective half cells of the battery during charge-discharge processes, as described in reactions 1 and 2.

Reaction 1 of positive electrode is as follows:

$$
\mathrm{VO}^{2+}+\mathrm{H}_{2} \mathrm{O} \underset{\text { discharge }}{\stackrel{\text { charge }}{\rightleftarrows}} \mathrm{VO}_{2}^{+}+2 \mathrm{H}^{+}+\mathrm{e}^{-}
$$

Reaction 2 of negative electrode is as follows:

$$
\mathrm{V}^{3+}+\mathrm{e}^{-} \underset{\text { discharge }}{\stackrel{\text { charge }}{\rightleftarrows}} \mathrm{V}^{2+}
$$

The VRB performance is generally determined by its coulombic efficiency (CE), voltage efficiency (VE), and energy efficiency (EE). CE is mainly affected by the rate of cross-mixed vanadium ion, indicating the capacity loss, and VE is determined by the thermodynamic reduction potential of the redox couples in each half cell and the overpotential of the cell. EE, which is calculated from CE and VE, is the key parameter to evaluate an energy storage system as an indicator of energy loss in charge-discharge processes [5].

Ion exchange membrane (IEM) is one of the key constituents in VRB system and separates between positive and negative electrolytes, preventing cross mixing of two electrolytes as well as providing the proton conduction. The resulting performance of the VRB is greatly affected by the properties of the IEM [12]. An ideal membrane for VRB should possess the following properties: (i) low permeation rates of vanadium ions and water to minimize self-discharge of the battery and allow high coulombic efficiency; (ii) high ionic conductivity for the transport of the charge-carrying ions such as $\mathrm{H}^{+}, \mathrm{SO}_{4}{ }^{2-}$, and $\mathrm{HSO}_{4}{ }^{-}$, which are needed to complete the electric circuit; (iii) minimized area resistance to reduce the voltage efficiency loss resulting from ohmic polarization; (iv) excellent chemical stability to ensure the battery's life time, because VRB membranes are operated in sulfuric acid medium in the presence of strong oxidizing vanadium ion solutions; (v) the low cost for commercializing VRB technology. The membranes commonly used in VRB are 


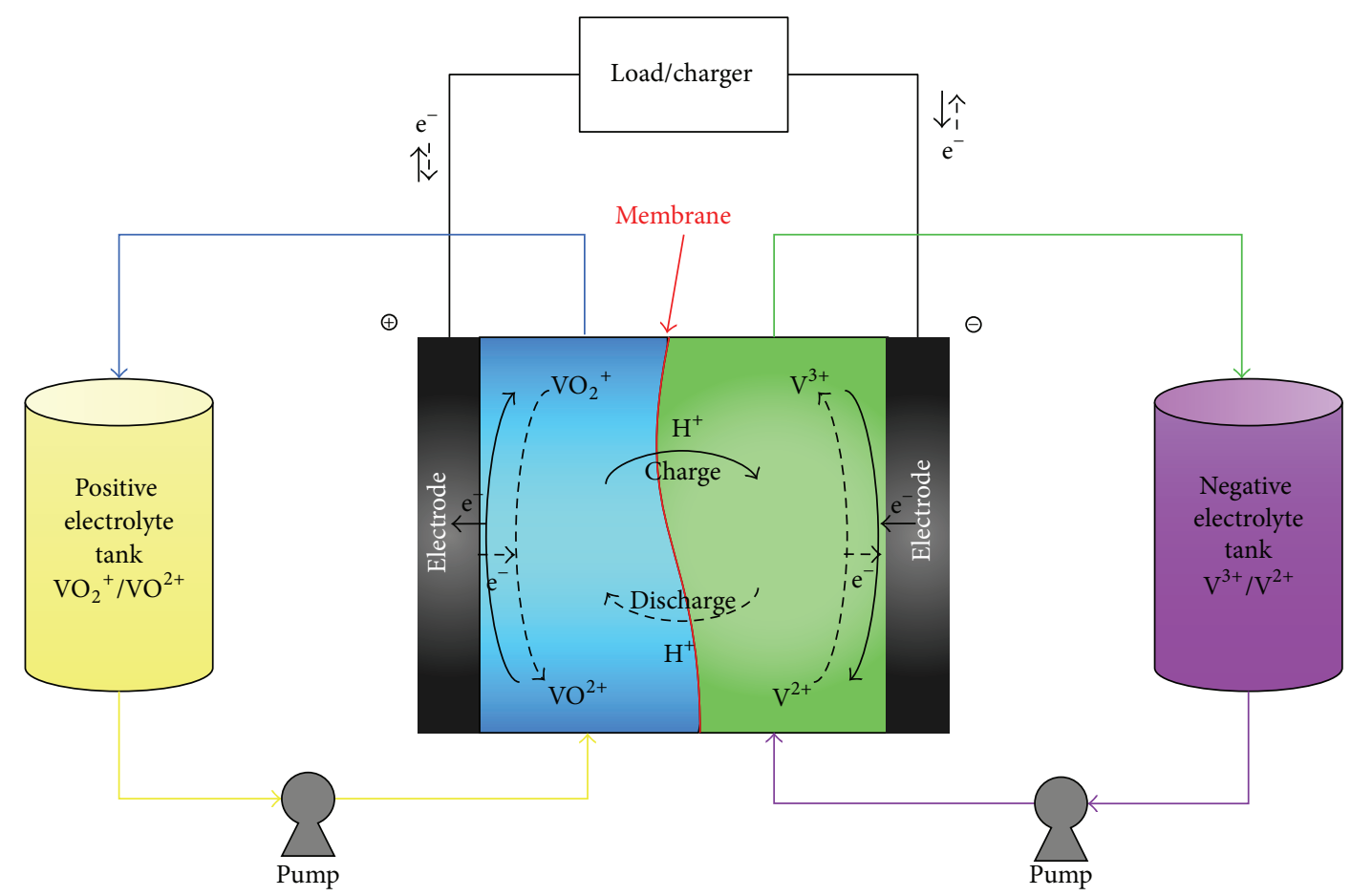

FIGURE 1: The principle of vanadium redox flow battery.

perfluorosulfonic acid (PFSA) membranes such as Dupont's Nafion due to its high chemical and mechanical stability and high proton conductivity. However, there are serious drawbacks in the Nafion membrane, which are the extremely high cost and high vanadium crossover. Nafion membrane accounts for $10-15 \%$ of the total cost of the battery system and $40 \%$ of the total cost of a VRB cell stack [13]. Also, the high vanadium ion permeability can lead to the decrease of CE and EE of VRB. Thus, Nafion is limited for broad commercialization of VRB systems.

As alternative to PFSA membranes, various hydrocarbonbased membranes, such as sulfonated poly(arylene ketone)s $[14,15]$, sulfonated poly(arylene sulfone)s [16-18], sulfonated polyimides [19], and poly(phthalazinone ether ketone ketone) $[20,21]$ membranes, have been widely investigated owing to their low vanadium ions permeability and low cost [22-24]. Despite many advantages, hydrocarbon-based membranes are still difficult to apply to the VRB system. This is because hydrocarbon-based membranes generally exhibit the lower chemical and oxidative stability mainly due to the susceptibility of the polymer backbone to attack of $\mathrm{H}_{2} \mathrm{SO}_{4}$ and $\mathrm{V}^{5+}$ in the VRB electrolytes $[25,26]$. However, the exact degradation mechanism was not fully understood yet [2729]. In particular, the poor water channel formation due to weak phase separation between hydrophilic and hydrophobic moieties resulted in relatively low proton conductivities even at high IECs [30], although sulfonated hydrocarbon membranes have reduced vanadium ion permeability compared with Nafion membranes.

To overcome the aforementioned issues, many attempts have been made via the preparation of nanostructured membranes which include Nafion hybrid membranes [31-35], hydrocarbon-based nanocomposite membranes
[2, 28, 36-44], amphoteric ion exchange membranes [4549], and nonionic membranes [50-56]. This review focuses on recent progress in developing various nanocomposite membranes with properties that make them attractive for VRB applications. And the respective object and property of functionalized nanocomposite membranes and the potential for VRB applications will be addressed. The idea of hybrid and composite membranes was inspired by the extensive previous researches to develop Nafion composite membranes for direct methanol fuel cell (DMFC) applications [57-67], which generally uses some interaction between organic or inorganic components and the sulfonic acid groups of IEMs. The introduction of nanofillers leads to a reduction of methanol crossover by blocking the hydrophilic clusters of Nafion membranes. This principle has also been applied in VRB applications, and thus decreased vanadium ion permeability with minimized proton conductivity loss leads to the improvement of VRB performance. Similarly, ion exchange membranes for VRB application have been developed by the pore-filling method [68, 69], polymer blending [22, 70], and the inorganic nanofiller doping technique $[38,71,72]$. However, the commercialization of VRB is still limited due to the lack of low cost, low vanadium ion permeability or high VRB performance. More recently, hybrid and composite membranes have been functionalized to further improve the performance of VRB system by decreasing the vanadium ion permeability and increasing the proton conductivity.

\section{Membrane for VRB}

2.1. Nanocomposite Membrane. Nafion was the most commonly used proton exchange membrane due to its proton 


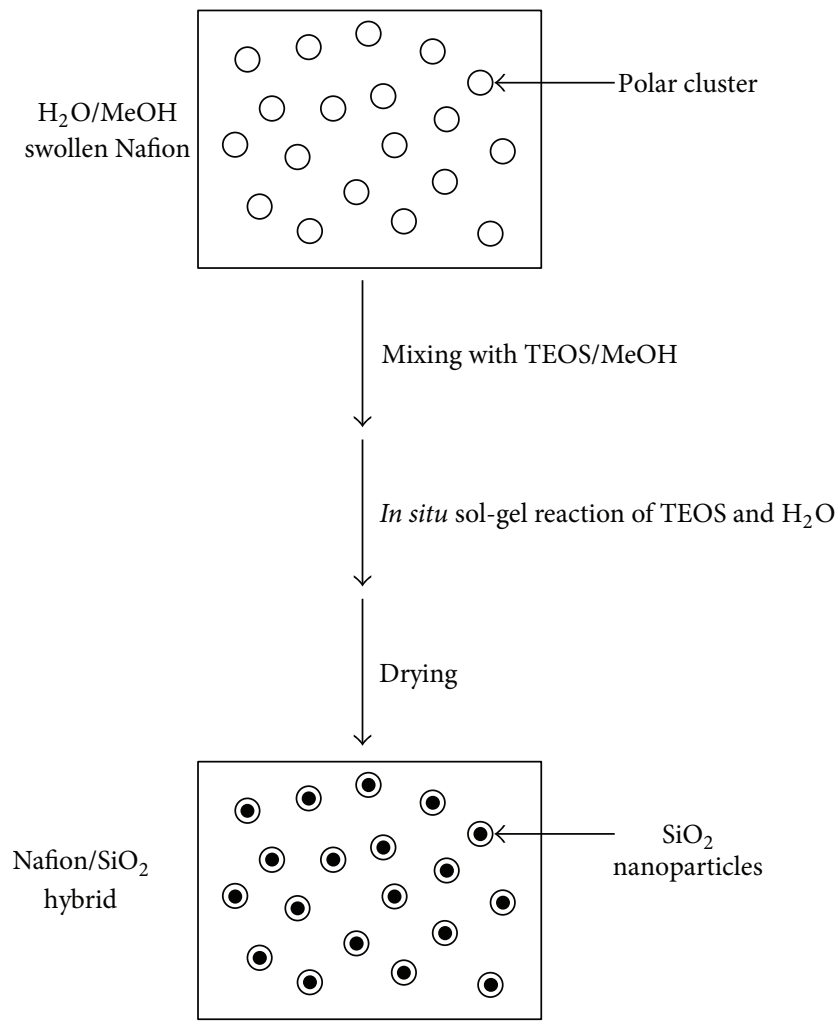

Figure 2: Preparation of Nafion/ $\mathrm{SiO}_{2}$ hybrid membrane.

conductivity and good chemical stability in strong acid and oxidation condition. However, it showed low ion selectivity between proton and vanadium ions in VRB system owing to the crossover of vanadium ion, which causes significant performance drop. This is due to its specific morphology having large size of hydrophilic channel originated from the strong nanophase separation of hydrophobic Teflon backbone and highly acidic sulfonic acid groups. To improve the performance of VRB by reducing the permeation of the vanadium ions, various Nafion nanocomposite membranes have been proposed.

Qiu and coworkers filled the polar clusters (pores) of the origin Nafion with $\mathrm{SiO}_{2}$ nanoparticles by in situ solgel reaction with TEOS (tetraethoxysilane) (Figure 2) [31], which was inspired by the pioneer work by Mauritz et al. [6365]. The various properties of $\mathrm{Nafion} / \mathrm{SiO}_{2}$ hybrid membrane containing $9.2 \mathrm{wt} \%$ of $\mathrm{SiO}_{2}$ such as ion exchange capacity (IEC), proton conductivity, water uptake, vanadium ion permeability, and cell performance are compared with the pristine Nafion membrane. The hybrid membrane showed lower vanadium ion permeability and water uptake than the pristine Nafion membrane, while its IEC and proton conductivity were similar to those of the pristine Nafion membrane. In the results of the VRB performance tests, the hybrid membrane exhibited excellent performance in comparison with Nafion membrane at all current densities from $10 \mathrm{~mA} \cdot \mathrm{cm}^{-2}$ to $80 \mathrm{~mA} \cdot \mathrm{cm}^{-2}$ owing to suppression of the crossover of vanadium ions. At $20 \mathrm{~mA} \cdot \mathrm{cm}^{-2}$, both the VRB with $\mathrm{Nafion} / \mathrm{SiO}_{2}$ hybrid membrane and VRB with Nafion membrane showed a maximum EE of the VRB $(79.9 \%$ and
$73.8 \%$, resp.). Also, the cycle performance for VRB with Nafion $/ \mathrm{SiO}_{2}$ hybrid membrane was not nearly decay of $\mathrm{CE}$ and EE up to 100 cycles at $60 \mathrm{~mA} \cdot \mathrm{cm}^{-2}$, which means the hybrid membrane has good chemical stability in vanadium and acid solutions.

Shul and Chu fabricated the Nafion/graphene oxide (GO) layered structure membrane by coating the pristine Nafion 117 membrane with the Nafion/GO emulsion solution [73]. GO has a two-dimensional layered structure, which can serve as an effective barrier to the transport of vanadium ions due to the significant increase in tortuosity [2]. Also, due to the hydrophilic properties of GO and the existence of oxygen function groups on the surface of GO, GO-Nafion membrane showed slightly higher water uptake and IEC than the pristine Nafion membrane. Although the IEC was not changed significantly, the permeability of the $\mathrm{VO}^{2+}$ ion decreased dramatically from $20.5 \times 10^{-7}$ to $6.1 \times 10^{-7} \mathrm{~cm}^{2} \cdot \mathrm{min}^{-1}$ by GO layer blocking vanadium ions. The VRB single cell performance of the GO-Nafion membrane exhibited higher CE compared to the Nafion membrane, while the VE of the GO-Nafion membrane was lower. This is due to the increase of internal resistance as well as the decrease of vanadium ion permeability by applying another layer in the Nafion membrane. As a result, the EE of the GO-Nafion membrane was higher than that of the Nafion membrane at low and medium current density except at $80 \mathrm{~mA} \cdot \mathrm{cm}^{-2}$.

In 2015, Yang and colleagues reported the colloidal zeolite-Nafion composite membrane synthesized with a twolayer structure consisting of a top layer of colloidal silicalite in Nafion matrix and a base layer of pure Nafion [74]. The colloidal silicalite-Nafion composite membranes with overall zeolite nanoparticle contents of $5 \mathrm{wt} \%$ and $15 \mathrm{wt} \%$, which were denoted by ZNM-5 and ZNM-15, were compared with the Nafion membrane. The same group previously studied the purely inorganic, molecular sieve zeolite membranes as a new type of highly proton-selective IEMs in the VRB and demonstrated great potential as effective IEMs in VRB [55, 56]. Due to the intracrystalline pores of silicalite (dia. $0.56 \mathrm{~nm}$ defined by 10 -member rings) which were impermeable to the hydrated multivalent metal ions but permeable to $\mathrm{H}_{3} \mathrm{O}^{+}$, the composite membrane exhibited higher $\mathrm{H}^{+} / \mathrm{VO}^{2+}$ ion transport selectivity (defined as the ratio of the slope for $\mathrm{H}^{+}$ to that for $\mathrm{VO}^{2+}$ in the permeation curves) than the Nafion membrane. The ZNM-15 with a more compact colloidal silicalite layer showed higher $\mathrm{H}^{+} / \mathrm{VO}^{2+}$ ion transport selectivity than ZNM-5. However, the total resistance of VRB cell with ZNM-15 (3.40 $\Omega$ ) was much higher than that of the Nafion $117(1.98 \Omega)$ and ZNM-5 (1.72 $\Omega$ ) because ZNM-15 had much higher content of silicalite nanoparticle. ZNM-5 indicated lower electrical resistance than the Nafion 117 because ZNM5 was overall much thinner with small silicalite content. The ZNM-5 membrane achieved higher CE, VE, and EE for the VRB than the Nafion 117 and ZNM-15 membranes. A 30day continuous cyclic operation test indicated quite stable EE value of the ZNM-5 equipped VRB with a slight increase in $\mathrm{CE}$ and a slight decrease in VE, which demonstrated good chemical stability of the silicalite-Nafion composite membrane. 


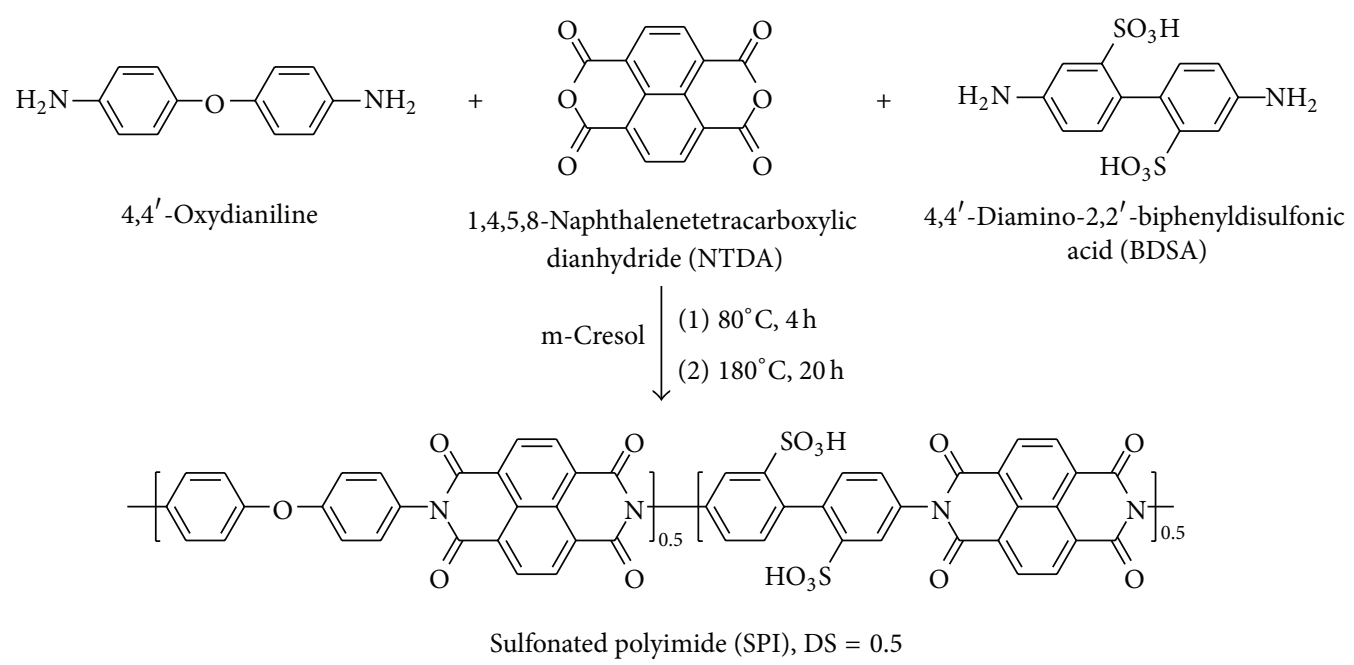

(a)
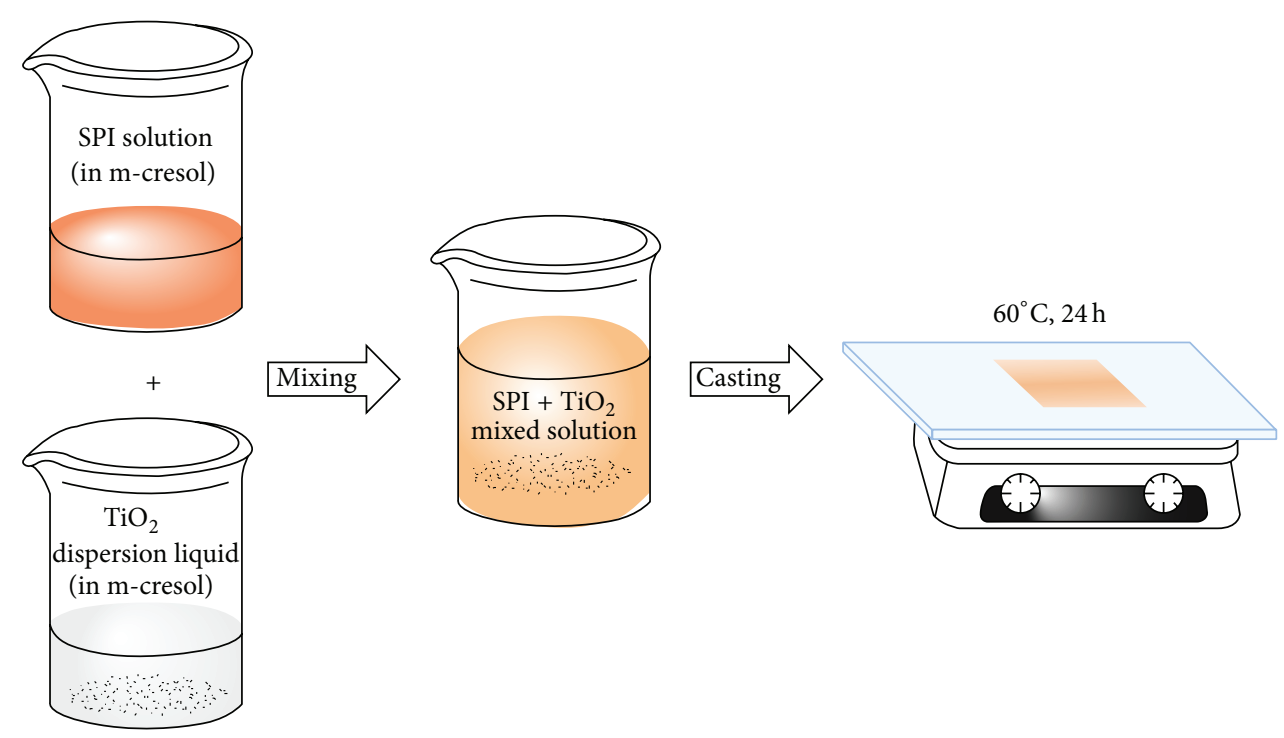

(b)

FIGURE 3: Schematic illustration of (a) SPI and (b) $\mathrm{SPI}^{\mathrm{T}} \mathrm{TiO}_{2}$ composite membrane.

Sulfonated aromatic polymer membranes based on nonfluorinated polymer, such as sulfonated poly(arylene ketone)s (SPAK)s including sulfonated poly(ether ether ketone) (SPEEK) and sulfonated poly(imide) (SPI), have been explored to reduce the cost of IEMs in VRB system as attractive alternatives to Nafion. This is because they possess excellent mechanical properties, high chemical stability under acidic conditions, and low cost and very low vanadium ion permeability. However, the properties of SPAK were highly dependent on the degree of sulfonation (DS). SPAK membranes with high DS exhibited not only higher proton conductivity, but also higher swelling, larger vanadium ion crossover, and lower mechanical strength. And the antioxidant ability of sulfonated aromatic polymer membranes was poorer compared with Nafion membrane. In order to overcome this dilemmatic problem and enhance the antioxidant ability, various nanoparticles were incorporated into the SPAK membrane.
As shown in Figure 3, Zhang and coworkers prepared $\mathrm{SPI} / \mathrm{TiO}_{2}$ composite membrane through blend technique by using $\mathrm{TiO}_{2}$ due to properties of mesoporous $\mathrm{TiO}_{2}$ particle such as good stability, easy availability, and low price [43]. The physicochemical properties of SPI/TiO ${ }_{2}$ composite membrane were compared to SPI and Nafion 117 membranes. The SPI/TiO 2 composite membrane exhibited lower water uptake and swelling ratio than the pure SPI membrane due to the less hydrophilic $\mathrm{TiO}_{2}$. At room temperature, the proton conductivity of the $\mathrm{SPI} / \mathrm{TiO}_{2}$ membrane indicated $3.12 \times 10^{-2} \mathrm{~S} \cdot \mathrm{cm}^{-1}$, which was higher than plain SPI membrane $\left(2.47 \times 10^{-2} \mathrm{~S} \cdot \mathrm{cm}^{-1}\right)$. The synergistic effect between the hydrated sulfonic group and the hydrated mesoporous titanium dioxide particles facilitates the proton transport behavior through the mesoporous structure. Compared to Nafion 117 membrane, the proton conductivity of the $\mathrm{SPI} / \mathrm{TiO}_{2}$ membrane was a little lower than Nafion $117(5.82 \times$ $10^{-2} \mathrm{~S} \cdot \mathrm{cm}^{-1}$ ) due to the unique hydrophilic-hydrophobic 


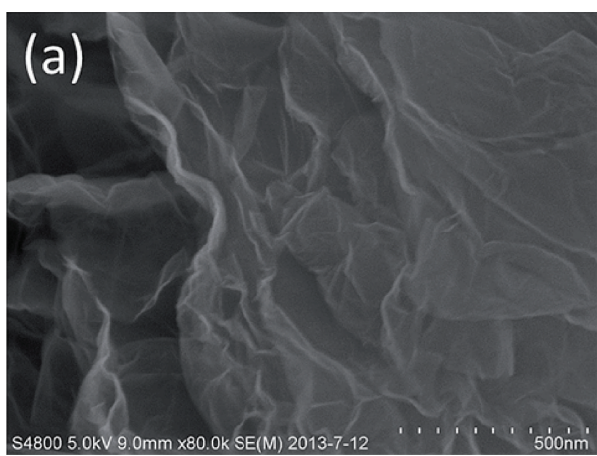

(a)

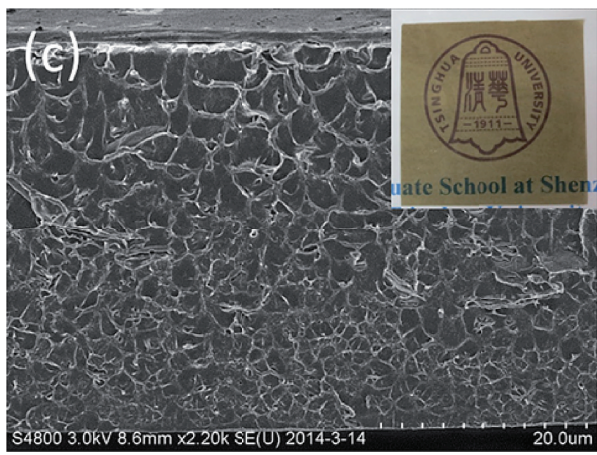

(c)

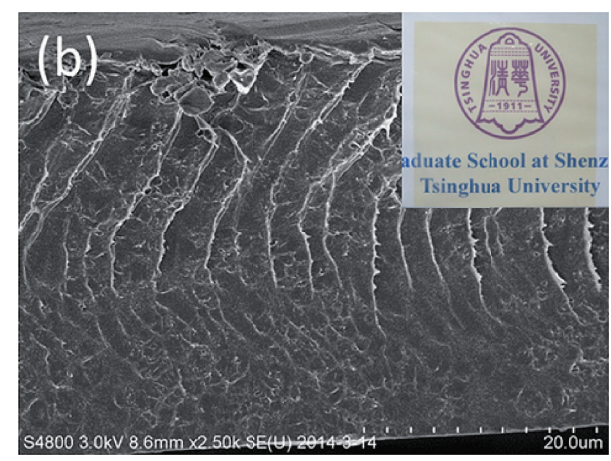

(b)

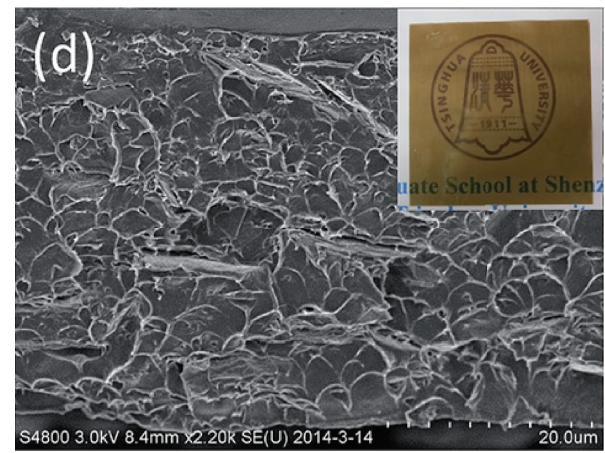

(d)

FIGURE 4: SEM images of (a) GO nanosheets and cross sections of (b) SPEEK, (c) SPEEK/GO2, and (d) SPEEK/GO3 membranes. The insets are the corresponding digital photos of the membranes. The scale bar in (a) is $500 \mathrm{~nm}$, while that in (b), (c), and (d) is $20 \mu \mathrm{m}$, reproduced with permission of RSC [33].

structure of Nafion. Nevertheless, the ion selectivity of $\mathrm{SPI} / \mathrm{TiO}_{2}$ membrane was the highest on account of the vanadium ion permeability. The vanadium ion permeability of SPI/TiO ${ }_{2}$ membrane was much lower than that of Nafion 117 membrane. Also, the vanadium resistance of $\mathrm{SPI} / \mathrm{TiO}_{2}$ membrane was higher than pure SPI membrane due to the better size stability of the composite membrane as presented in physicochemical properties. As a result, the VRB with $\mathrm{SPI} / \mathrm{TiO}_{2}$ composite membrane was always higher in $\mathrm{CE}$ and EE than that with Nafion 117 membrane especially at low current densities and the OCV performance of the VRB with the $\mathrm{SPI} / \mathrm{TiO}_{2}$ composite membrane showed superior performance than that with Nafion 117 membrane.

In the following publications, Qiu's group fabricated SPEEK/Graphene (SPEEK/G) composite membrane [2]. Graphene also had a unique two-dimensional layered structure like GO, which was stable under ambient conditions and had good mechanical property. Although the graphene ratio of SPEEK/G composite membrane was very small amount of about $1 \mathrm{wt} \%$, the effect of graphene in SPEEK membrane could be confirmed by the results of physicochemical properties, permeability of vanadium ions, selectivity, and VRB cell performance. The SPEEK/G composite membrane showed good physicochemical properties for VRB application. Despite a lower proton conductivity than Nafion 117, ion selectivity of SPEEK/G composite membrane $\left(1.62 \times 10^{4} \mathrm{~S} \cdot \mathrm{min} \cdot \mathrm{cm}^{-3}\right)$ was higher than Nafion $117(0.95$ $\times 10^{4} \mathrm{~S} \cdot \mathrm{min} \cdot \mathrm{cm}^{-3}$ ) due to a sharp decrease of vanadium ion permeability. VRB single cell performance of SPEEK/G composite membrane exhibited a lower self-discharge rate as well as the CE of $96.4 \%$ and $\mathrm{EE}$ of $83.8 \%$ at the current density of $80 \mathrm{~mA} \mathrm{~cm}^{-2}$, which were higher than those of Nafion 117 (92.8\% and $79.5 \%$, resp.).

And then the same group reported a series of SPEEK/ Graphene oxide nanocomposite membranes with various amounts of GO loadings [37]. Beyond the formation of an effective barrier for the transport of vanadium ions by the two-dimensional layered structure of GO nanosheets, the incorporation of GO into SPEEK membranes for VRB can form the hydrophobic/hydrophilic phase separation structure because the hydrophilic surface of GO, which is originated from the oxygen-containing functional groups of GO, was prone to form hydrogen bonds with polymer chains and consequently enhance ion selectivity. The strong interfacial interaction between GO and the SPEEK membrane served the uniform dispersion of GO nanosheets in the polymer matrix which improved the mechanical stability of the pristine SPEEK membranes due to the great mechanical strength of GO. The SPEEK/GO composite membranes were prepared with $1,2,3$, or $5 \mathrm{wt} \%$ of GO and denoted by SPEEK/GOX, where $X$ was the weight ratio of GO (Figure 4). With increasing GO content, the water uptake, swelling ratio, and IEC of SPEEK/GO composite membrane increased due to hydrophilic nature of GO, whereas the proton conductivity decreased by blocking effect of the GO filler. The permeation of $\mathrm{VO}^{2+}$ across the composite membranes decreased with 
TABLE 1: Comparison of general properties between Nafion 117 and various nanocomposite membranes.

\begin{tabular}{|c|c|c|c|c|c|}
\hline Membranes [ref. \#] & $\begin{array}{l}\mathrm{VO}^{2+} \text { permeability } \\
\left(\times 10^{-7} \mathrm{~cm}^{2} \cdot \mathrm{min}^{-1}\right)\end{array}$ & $\begin{array}{l}\text { Conductivity } \\
\left(\mathrm{mS} \cdot \mathrm{cm}^{-1}\right) / \\
\text { area resistance } \\
\left(\Omega \cdot \mathrm{cm}^{2}\right)\end{array}$ & $\begin{array}{c}\mathrm{CE}(\%) \\
{\left[@ 40 \mathrm{~mA} \cdot \mathrm{cm}^{-2}\right]}\end{array}$ & $\begin{array}{c}\mathrm{VE}(\%) \\
{\left[@ 40 \mathrm{~mA} \cdot \mathrm{cm}^{-2}\right]}\end{array}$ & $\begin{array}{c}\mathrm{EE}(\%) \\
{\left[@ 40 \mathrm{~mA} \cdot \mathrm{cm}^{-2}\right]}\end{array}$ \\
\hline Nafion 117 [31] & $\approx 30$ & $58.7 /-$ & $\approx 87$ & $\approx 82.5$ & $\approx 72.5$ \\
\hline Nafion $/ \mathrm{SiO}_{2}[31]$ & $\approx 3.8$ & $56.2 /-$ & $\approx 90$ & $\approx 85$ & $\approx 76.5$ \\
\hline Nafion/GO [73] & 6.1 & $\approx 62 /-$ & $\approx 90$ & $\approx 87.5$ & $\approx 79$ \\
\hline ZNM-5 [74] & - & $-/ 0.55$ & $\approx 92$ & $\approx 88$ & $\approx 81$ \\
\hline $\mathrm{SPI} / \mathrm{TiO}_{2}[34]$ & 2.02 & $31.2 /-$ & $\approx 96.5$ & $\approx 77$ & $\approx 79$ \\
\hline SPEEK/G [2] & 8.7 & $14.1 / 1.28$ & $\approx 94.5$ & $\approx 91$ & $\approx 89$ \\
\hline SPEEK/GO2 [37] & 7.9 & $14.9 /-$ & $\approx 94$ & $\approx 92$ & $\approx 88$ \\
\hline SPEEK/GO2@PTFE [37] & - & $-1-$ & $\begin{array}{c}98.4 \\
{\left[@ 80 \mathrm{~mA} \cdot \mathrm{cm}^{-2}\right]}\end{array}$ & $\begin{array}{c}82.5 \\
{\left[@ 80 \mathrm{~mA} \cdot \mathrm{cm}^{-2}\right]}\end{array}$ & $\begin{array}{c}81.2 \\
{\left[@ 80 \mathrm{~mA} \cdot \mathrm{cm}^{-2}\right]}\end{array}$ \\
\hline Silica nanocomposite AEM [75] & 4.24 & $-/ 1.088$ & $\approx 91$ & $\approx 80$ & 73 \\
\hline
\end{tabular}

increasing of the GO weight ratio because the impermeable two-dimensional layered GO nanosheets can serve as effective barriers and the interfacial interaction between GO and SPEEK matrix restricts the formation of hydrophilic channels used for the transport of vanadium ions. Based on all the above results, the SPEEK/GO2 composite membrane showed the highest selectivity of $1.88 \times 10^{4} \mathrm{~S} \cdot \mathrm{min} \cdot \mathrm{cm}^{-3}$, which was about two times higher than that of Nafion 117 membrane $\left(0.91 \times 10^{4} \mathrm{~S} \cdot \mathrm{min} \cdot \mathrm{cm}^{-3}\right)$. The CE and EE of VRB single cell performance with SPEEK/GO2 membrane (96.9\% and $84.2 \%$, resp.) were much higher than those with Nafion 117 membrane (92.8\% and 79.5\%, resp.) at the current density of $80 \mathrm{~mA} \cdot \mathrm{cm}^{-2}$. The results of chargedischarge cycle performance showed the capacity retention after 300 cycles of SPEEK/GO2 and Nafion 117 was $50.1 \%$ and $16.2 \%$, respectively. The SPEEK/GO2 composite membrane demonstrated the excellent VRB cell performance in comparison to Nafion 117. In addition, a pore-filling membrane (denoted as SPEEK/GO2@PTFE) was fabricated by using poly(tetrafluoroethylene) (PTFE) as the porous substrate to further improve the cycling stability of SPEEK/GO composite membrane for application in long-life VRB systems. Porous PTFE film was a robust host with a highly porous structure, which can contribute to the improvement in mechanical strength and chemical stability of the SPEEK/GO2@PTFE. The SPEEK/GO2@PTFE membrane exhibited higher CE and EE of $98.4 \%$ and $81.2 \%$ due to high ion selectivity $(1.92 \times$ $10^{4} \mathrm{~S} \cdot \mathrm{min} \cdot \mathrm{cm}^{-3}$ ) and the capacity retention of the resultant pore-filling membrane was $78.7 \%$, higher than SPEEK/GO2 and Nafion 117 membranes (Figure 5). Table 1 summarizes the basic properties of nanocomposite and Nafion 117 membranes and VRB performance employing them.

Recent studies suggested anion exchange membrane (AEM) as another hydrocarbon-based membrane, which exhibited lower vanadium ion permeability than cation exchange membranes. The AEM tends to suppress vanadium crossover due to the charge repulsion effect, known as Donnan exclusion, between positively charged groups of the membrane and the vanadium ions. Leung et al. modified an AEM (Fumasep's FAP) via in situ sol-gel reaction of TEOS to minimize the crossover of vanadium ions [75].
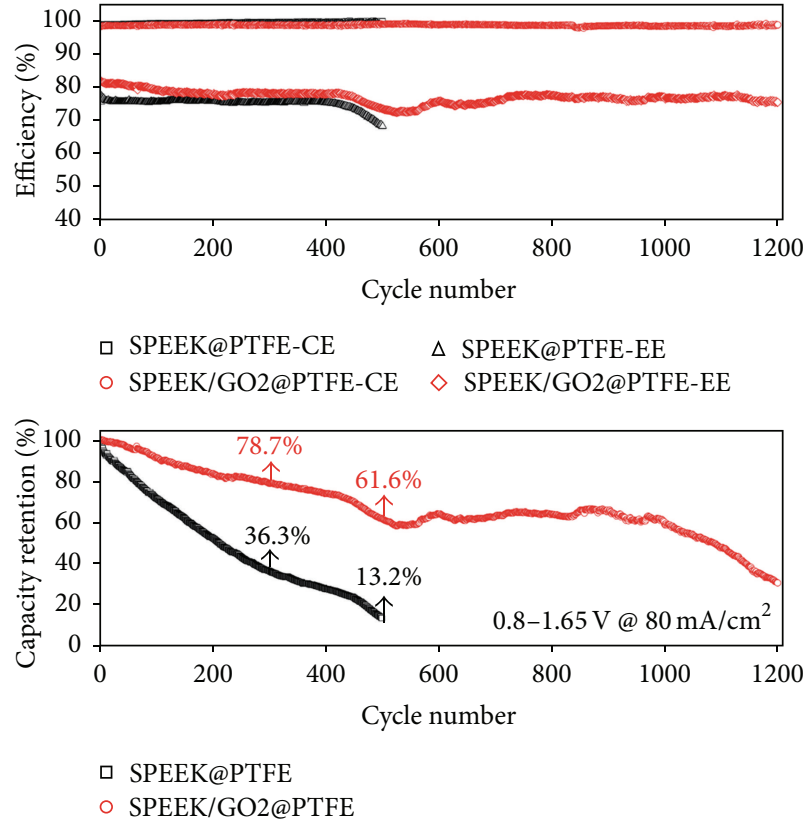

FIGURE 5: Cycle performance of VRBs with SPEEK@PTFE membrane and SPEEK/GO2@PTFE membrane, reproduced with permission of RSC [33].

A silica nanocomposite AEM (c.a. $5.60 \mathrm{wt} \%$ by $30 \mathrm{sec}$ solgel reaction) was compared with Nafion 115 and pristine AEM. The permeability of vanadium ion showed a decreasing order of Nafion $115\left(1.62 \times 10^{-6} \mathrm{~cm}^{2} \cdot \mathrm{min}^{-1}\right)>$ pristine AEM $\left(5.24 \times 10^{-7} \mathrm{~cm}^{2} \cdot \mathrm{min}^{-1}\right)>$ silica nanocomposite AEM $(4.24 \times$ $\left.10^{-7} \mathrm{~cm}^{2} \cdot \mathrm{min}^{-1}\right)$. The positive charged groups within the membrane repelled vanadium cations by mean of electrostatics. Besides, the silica nanoparticles within the cannel network or hydrophilic clusters of the modified AEM blocked diffusion of vanadium ion. Due to the lowest vanadium permeability, the silica nanocomposite AEM exhibited the lowest self-discharge rate and the highest $\mathrm{CE}$. The VE of the silica nanocomposite AEM was slightly lower than those of the pristine AEM and Nafion 115 owing to the increased 


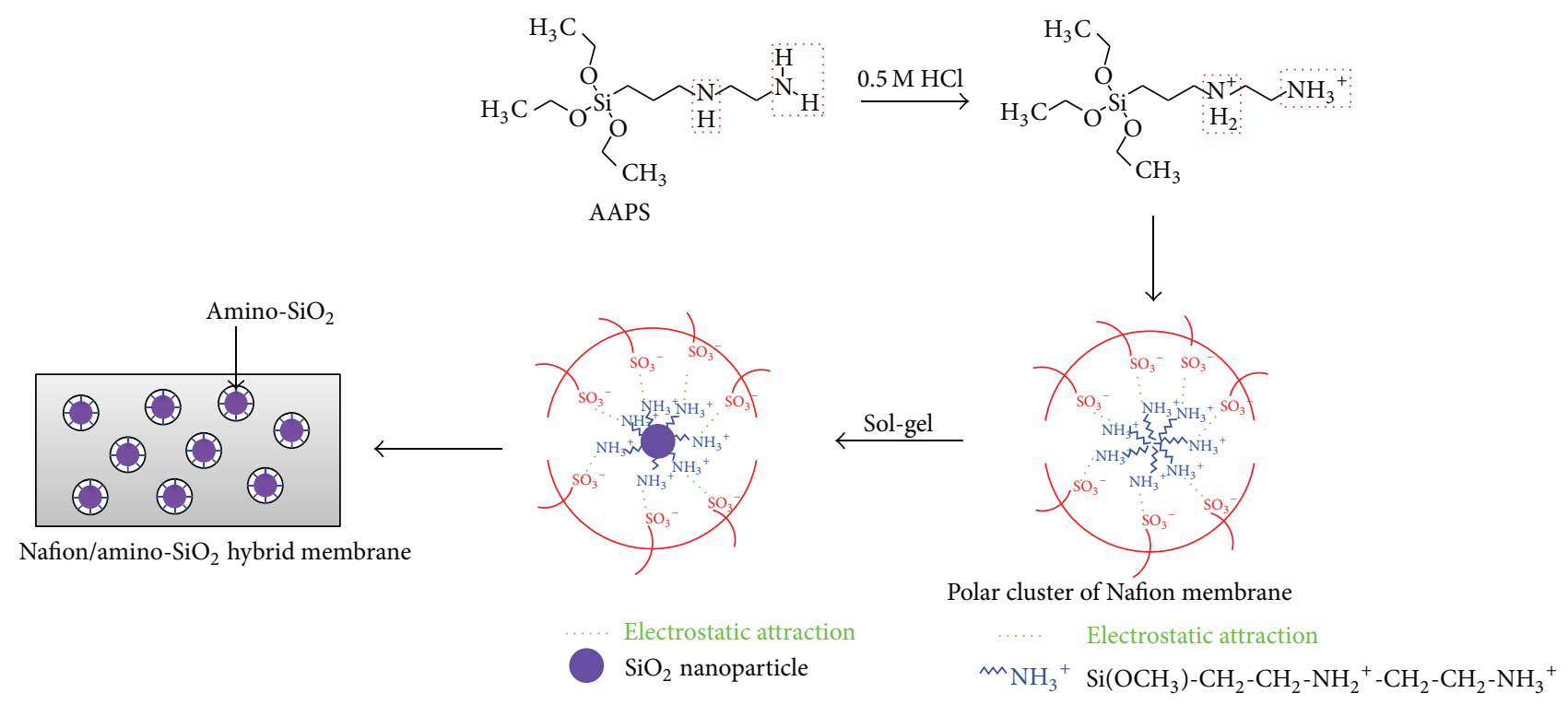

FIGURE 6: Schematic illustration of the preparation of Nafion/amino- $\mathrm{SiO}_{2}$ hybrid membrane.

area resistance after silica modification. As a result, the EE of silica nanocomposite AEM was found to be higher than that of Nafion 115 but lower than that of pristine AEM. Nevertheless, the silica nanocomposite AEM can be an alternative candidate for VRB application because the discharge capacity of the VRB with the silica nanocomposite AEM was the highest in comparison to the pristine AEM and Nafion 115.

2.2. Functionalized Nanocomposite Membrane. There has been extensive research on the Nafion/inorganic nanocomposite membranes to reduce the vanadium permeability including recasting with inorganic nanoparticles and in situ sol-gel reaction to incorporate inorganic nanoparticles within the pores of Nafion [31-33, 76, 77]. However, the Nafion/inorganic nanocomposite membranes decreased the crossover of vanadium as well as proton conductivity. To solve the conflict between membrane ion selectivity and conductivity, Yang's group prepared the Nafion/amino$\mathrm{SiO}_{2}$ hybrid membrane through the sol-gel reactions of $\mathrm{N}$ (2-aminoethyl)-3-aminopropyltrimethoxysilane (AAPS) as shown in Figure 6 [78]. The IEC of the hybrid membrane was increased due to the amino group of the amino- $\mathrm{SiO}_{2}$, which can improve the ion selectivity while keeping the conductivity nearly unchanged. The permeability of vanadium ions across the hybrid membrane $\left(2.32 \times 10^{-7} \mathrm{~cm}^{2} \cdot \mathrm{min}^{-1}\right)$ was lower than that across the pristine Nafion membrane $(8.65 \times$ $10^{-7} \mathrm{~cm}^{2} \cdot \mathrm{min}^{-1}$ ) because the amino- $\mathrm{SiO}_{2}$ nanoparticles were filled into the polar clusters of the Nafion membrane. The results of VRB single cell test indicated the Nafion/amino$\mathrm{SiO}_{2}$ hybrid membrane which showed higher $\mathrm{CE}, \mathrm{VE}$, and $\mathrm{EE}$ than the pristine Nafion at the current density ranging from 20 to $80 \mathrm{~mA} \cdot \mathrm{cm}^{-2}$. Higher CE was attributed to less crossover of vanadium ions. The higher VE of the VRB with the hybrid membrane was affected by conductivity, which depended on water uptake and IEC. Because the IEC was increased by the amino groups of amino- $\mathrm{SiO}_{2}$ in spite of lower water uptake,
Nafion/amino- $\mathrm{SiO}_{2}$ hybrid membrane exhibited a higher VE. As a result, the EE of the VRB with Nafion/amino- $\mathrm{SiO}_{2}$ hybrid membrane exhibited a $4.2 \%$ increase compared with the pristine Nafion membrane at $80 \mathrm{~mA} \cdot \mathrm{cm}^{-2}$.

In the follow-up publication, Cao and coworkers prepared a series of novel acid-base hybrid membranes (SPI/PEI-rGO) based on sulfonated polyimide (SPI) with polyethyleneimine-functionalized reduced graphene oxide (PEI-rGO) by solution-casting method [79], which was inspired by the SPEEK/polyetherimide acid-base blend membrane developed by Liu et al. [23]. Figure 7 gave the detailed preparation process of PEI-rGO and SPI matrix. The appearing basic groups such as $\mathrm{NH}_{2}$-GO further provided the positive charge, which can expect a Donnan exclusion effect on the vanadium ion. The SPI/PEI-rGO membranes with various contents of PEI-rGO were denoted by SPI/PEI-rGO- $X$, where $X(X=0.5,1,2$ and 4$)$ was the mass ratio of PEI-rGO to SPI. The physicochemical properties such as water uptake, swelling ration, and IEC of membrane decreased with the PEI-rGO contents increasing. The electrostatic interaction between $-\mathrm{NH}_{2}$ and $-\mathrm{SO}_{3} \mathrm{H}$ in the interfacial zone decreased the water-absorbing ability of the $-\mathrm{SO}_{3} \mathrm{H}$ groups, further restricted the mobility of polymer chains, and played a dilution effect on $-\mathrm{SO}_{3} \mathrm{H}$ in the hybrid membranes. The proton conductivity of SPI/PEI-rGO-0.5 hybrid membrane was similar to that of the pure SPI membrane, but the proton conductivity firstly increased and then decreased with the content of PEI-rGO increasing. This is due to the acid-base pairs formed by the proton acceptor $\left(-\mathrm{NH}_{2}\right.$ groups) and the proton donator (- $\mathrm{SO}_{3} \mathrm{H}$ groups) in the interfacial zone between PEI-rGO filler and SPI matrix, whereas the vanadium permeability decreased with the increasing PEI-rGO content, and the vanadium permeability of all hybrid membranes was much lower than that of Nafion 117 membrane. Firstly, an effective barrier was formed by the impermeable two-dimensional graphene-based filler, preventing vanadium ions from 


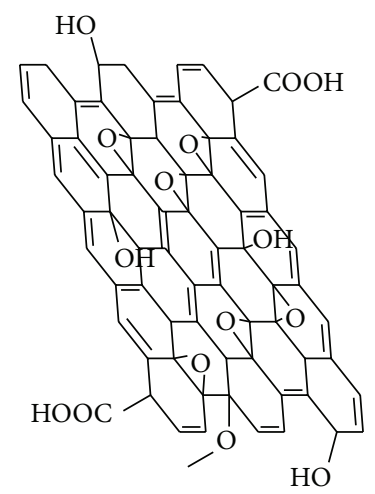

GO

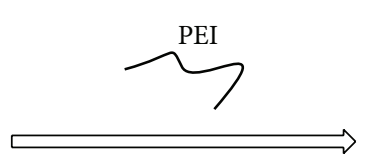

$100^{\circ} \mathrm{C}, 12 \mathrm{~h}$

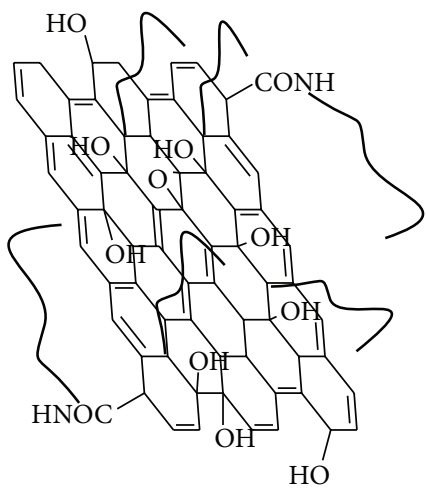

PEI-rGO<smiles>NCCNCCN(CCNCCN)CCN(CCNCCN)CCN(CN)CCN</smiles>

FIgUre 7: Schematic illustration of PEI-rGO.

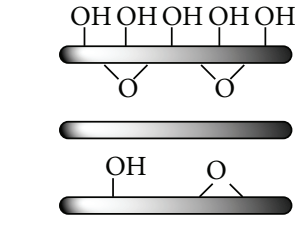

Molybdenum disulfide $\left(\mathrm{MoS}_{2}\right)$
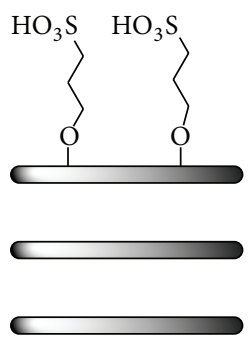

Sulfonated molybdenum disulfide $\left(\mathrm{s}-\mathrm{MoS}_{2}\right)$

FIgURE 8: The sulfonation process of molybdenum disulfide.

crossing the hybrid membranes due to the significant increase in tortuosity [37]. Secondly, the $-\mathrm{NH}_{3}{ }^{+}$groups on the surface of PEI-rGO prevented the vanadium ion crossover by Donnan exclusion effect, which means the positive charged $-\mathrm{NH}_{3}{ }^{+}$effectively hindered vanadium ions permeation under the strong electrostatic exclusion effect. Finally, the formation of transport channels to vanadium ions is restricted by the existing strong interfacial interaction between PEI-rGO and SPI matrix [80]. The selectivity, defined as the ratio of proton conductivity and vanadium ion permeability, of SPI/PEI-rGO membranes first increased with the PEI-rGO filler and then dropped. When $2 \mathrm{wt} \%$ PEI-rGO was incorporated into SPI matrix, the maximum value appeared owing to the good balance between proton conductivity and vanadium ion permeability. From results, SPI/PEI-rGO-2 membrane was investigated for the single cell performance of VRB. SPI/PEI-rGO-2 hybrid membrane exhibited higher VRB performance of CE (95\% versus 91\%) and EE $(75.6 \%$ versus $66.8 \%)$ than Nafion 117 membrane at
$40 \mathrm{~mA} \cdot \mathrm{cm}^{-2}$. Furthermore, the hybrid membrane showed a stable performance over 100-cycle charge-discharge tests.

More recently, $\mathrm{Li}$ et al. reported the composite membranes (SPI/s- $\mathrm{MoS}_{2}$ ) of sulfonated polyimide (SPI) and sulfonated molybdenum disulfide $\left(\mathrm{s}-\mathrm{MoS}_{2}\right)$ (Figure 8) for VRB application [81]. A new type of sulfonated $\mathrm{MoS}_{2}$ had graphene-like two-dimensional layered structure, which was advantageous to the proton transport. Also, s- $\mathrm{MoS}_{2}$ was in possession of good chemical stability, which can improve the chemical stability of SPI membrane. Finally, s-MoS contains sulfonic group $\left(-\mathrm{SO}_{3} \mathrm{H}\right)$ attached to its surface, which increased the proton conductivity and provided a strong interfacial interaction between s-MoS 2 and SPI due to the formation of hydrogen bond. The SPI/s- $\mathrm{MoS}_{2}$ composite membrane was compared to SPI, SPI/MoS ${ }_{2}$, and Nafion 117 membranes. The oxidative stability test of membranes, which was investigated by the weight retention of membranes and the color change of the $\mathrm{V}(\mathrm{V})$ solution after soaking membranes at $40^{\circ} \mathrm{C}$ for some time, showed the weight loss 
TABLE 2: Comparison of general properties between prefunctionalized nanocomposite and functionalized nanocomposite membranes.

\begin{tabular}{|c|c|c|c|c|c|}
\hline Membranes [ref. \#] & $\begin{array}{l}\mathrm{VO}^{2+} \text { permeability } \\
\left(\times 10^{-7} \mathrm{~cm}^{2} \cdot \mathrm{min}^{-1}\right)\end{array}$ & $\begin{array}{c}\text { Conductivity } \\
\left(\mathrm{mS} \cdot \mathrm{cm}^{-1}\right) / \\
\text { area resistance } \\
\left(\Omega \cdot \mathrm{cm}^{2}\right)\end{array}$ & $\begin{array}{c}\mathrm{CE}(\%) \\
{\left[@ 40 \mathrm{~mA} \cdot \mathrm{cm}^{-2}\right]}\end{array}$ & $\begin{array}{c}\mathrm{VE}(\%) \\
{\left[@ 40 \mathrm{~mA} \cdot \mathrm{cm}^{-2}\right]}\end{array}$ & $\begin{array}{c}\mathrm{EE}(\%) \\
{\left[@ 40 \mathrm{~mA} \cdot \mathrm{cm}^{-2}\right]}\end{array}$ \\
\hline Nafion/amino- $\mathrm{SiO}_{2}$ [78] & 2.32 & $-/ 3.45$ & $\approx 91$ & $\approx 79$ & $\approx 73$ \\
\hline SPI/PEI-rGO-2 [79] & $\approx 7.5$ & $\approx 6.2 /-$ & 95 & $\approx 79$ & 75.6 \\
\hline SPI/GO-4 [79] & - & $-1-$ & $\approx 90$ & $\approx 72.5$ & $\approx 70$ \\
\hline SPI/s- $-\mathrm{MoS}_{2}[81]$ & 1.23 & $27.5 /-$ & $\approx 91$ & $\approx 82$ & $\approx 75$ \\
\hline $\mathrm{SPI} / \mathrm{MoS}_{2}[81]$ & 2.02 & $21.5 /-$ & $\approx 89$ & $\approx 81$ & $\approx 72$ \\
\hline
\end{tabular}

of SPI/s- $\mathrm{MoS}_{2}$ membrane (2.29\%) was lower than both SPI (3.76\%) and SPI/MoS 2 membranes (2.81\%) after $360 \mathrm{~h}$. However, the yellow $\mathrm{V}(\mathrm{V})$ solution gradually became green since a small quantity of the $\mathrm{V}(\mathrm{V})$ ions was reduced to be $\mathrm{V}(\mathrm{IV})$ ions by membranes except Nafion 117, which means Nafion 117 membrane has the most excellent oxidative stability. The water uptake and swelling ratio of SPI/s- $\mathrm{MoS}_{2}$ membrane were lower than those of SPI and SPI/ $\mathrm{MoS}_{2}$ membranes due to the "blocking effect" of inorganic component and the interfacial adhesion between polymer matrix and inorganic component. The interfacial interaction of SPI/s- $\mathrm{MoS}_{2}$ membrane is stronger than that of $\mathrm{SPI} / \mathrm{MoS}_{2}$ membrane because the $\mathrm{s}-\mathrm{MoS}_{2}$ has more hydrogen bonding sites than $\mathrm{MoS}_{2}$ by the additional $-\mathrm{SO}_{3} \mathrm{H}$ groups of $s-\mathrm{MoS}_{2}$ as well as $-\mathrm{OH}$ groups of $\mathrm{MoS}_{2}$. The IEC value of SPI/s- $\mathrm{MoS}_{2}$ membrane was the highest among SPI/s- $\mathrm{MoS}_{2}, \mathrm{SPI} / \mathrm{MoS}_{2}$, the pure SPI, and Nafion 117 membranes due to the introduction of s$\mathrm{MoS}_{2}$ particles with sulfonic acid groups $\left(-\mathrm{SO}_{3} \mathrm{H}\right)$ as fixed charge sites. Although the proton conductivity of Nafion 117 exhibited the highest value of $5.82 \times 10^{-2} \mathrm{~S} \cdot \mathrm{cm}^{-1}$, the proton conductivity of SPI/s- $\mathrm{MoS}_{2}$ membrane was improved up to $2.75 \times 10^{-2} \mathrm{~S} \cdot \mathrm{cm}^{-1}$ in comparison with the pristine SPI $\left(2.27 \times 10^{-2} \mathrm{~S} \cdot \mathrm{cm}^{-1}\right)$ and SPI/MoS $\left(2.15 \times 10^{-2} \mathrm{~S} \cdot \mathrm{cm}^{-1}\right)$ membranes owing to the unique two-dimensional structure together with sulfonated acid groups of s-MoS 2 . A "blocking effect" of s-MoS $\mathrm{S}_{2}$ particles in the polymer led to a decrease in vanadium ion permeability of SPI/s- $\mathrm{MoS}_{2}$ membrane to $1.23 \times 10^{-7} \mathrm{~cm}^{2} \cdot \mathrm{min}^{-1}$, which was the lowest value among all membranes. Thus, SPI/s- $\mathrm{MoS}_{2}$ membrane presented the highest proton selectivity of $2.24 \times 10^{5} \mathrm{~S} \cdot \mathrm{min} \cdot \mathrm{cm}^{-3}$. Owing to the good balance of proton conductivity and vanadium ion permeability, the CE and EE of the VRB with SPI/s$\mathrm{MoS}_{2}$ membrane were higher than those with SPI/MoS 2 and Nafion 117 membranes, indicating great potential for long life VRB system. Table 2 summarizes the basic properties of functionalized nanocomposite membranes and VRB performance employing them, comparing with prefunctionalized nanocomposite membranes.

\section{Conclusion}

VRBs become more and more important as a promising choice for large-scale electrochemical energy storage systems. However, the VRB technology has not yet achieved a real breakthrough and further researches are required to reach full commercial potential. The IEM as a critical component of a
VRB is still the main factor which limits further commercialization. Perfluorosulfonic acid polymers with excellent long-term stability and high proton conductivity are the most often used ones, but much greater cost reduction and larger selectivity increase are necessary. Significant cost reduction and large performance improvement should be achieved for the membrane material.

This review shows the possible approaches for development of various nanocomposite membranes. Numerous modifications of Nafion proved that the modification was very effective in decreasing the vanadium ion permeability but usually accompanied the reduction of proton conductivity. Also, extensive studies on sulfonated hydrocarbon-based nanocomposite membranes are ongoing as low cost alternatives to Nafion membranes, but chemical stability issues still plague this search area of hydrocarbon membranes.

In conclusion, considering the ion selectivity and the energy efficiency, functionalized nanocomposite membranes show better performance than prefunctionalized nanocomposite membranes. Nevertheless, the nanocomposite membrane research for applications in VRB is still in its infancy, and more efforts need new strategies to design and prepare the next-generation membranes having outstanding VRB performance over long period of time.

\section{Conflict of Interests}

The author declares that there is no conflict of interests regarding the publication of this paper.

\section{Acknowledgment}

This work was supported by Kyonggi University Research Grant 2012.

\section{References}

[1] C. Ponce de León, A. Frías-Ferrer, J. González-García, D. Szánto, and F. Walsh, "Redox flow cells for energy conversion," Journal of Power Sources, vol. 160, no. 1, pp. 716-732, 2006.

[2] W. Dai, L. Yu, Z. Li et al., "Sulfonated Poly(Ether Ether Ketone)/Graphene composite membrane for vanadium redox flow battery," Electrochimica Acta, vol. 132, pp. 200-207, 2014.

[3] A. Chromik, A. R. dos Santos, T. Turek, U. Kunz, T. Häring, and J. Kerres, "Stability of acid-excess acid-base blend membranes 
in all-vanadium redox-flow batteries," Journal of Membrane Science, vol. 476, pp. 148-155, 2015.

[4] J. Xi, Z. Wu, X. Teng, Y. Zhao, L. Chen, and X. Qiu, "Selfassembled polyelectrolyte multilayer modified Nafion membrane with suppressed vanadium ion crossover for vanadium redox flow batteries," Journal of Materials Chemistry, vol. 18, no. 11, pp. 1232-1238, 2008.

[5] X. F. Li, H. M. Zhang, Z. S. Mai, H. Z. Zhang, and I. Vankelecom, "Ion exchange membranes for vanadium redox flow battery (VRB) applications," Energy \& Environmental Science, vol. 4, no. 4, pp. 1147-1160, 2011.

[6] C. Ding, H. Zhang, X. Li, T. Liu, and F. Xing, "Vanadium flow battery for energy storage: prospects and challenges," Journal of Physical Chemistry Letters, vol. 4, no. 8, pp. 1281-1294, 2013.

[7] H. Vafiadis and M. Skyllas-Kazacos, "Evaluation of membranes for the novel vanadium bromine redox flow cell," Journal of Membrane Science, vol. 279, no. 1-2, pp. 394-402, 2006.

[8] X. Luo, Z. Lu, J. Xi et al., "Influences of permeation of vanadium ions through PVDF-g-PSSA membranes on performances of vanadium redox flow batteries," Journal of Physical Chemistry B, vol. 109, no. 43, pp. 20310-20314, 2005.

[9] G. Oriji, Y. Katayama, and T. Miura, "Investigations on $\mathrm{V}(\mathrm{IV}) / \mathrm{V}(\mathrm{V})$ and $\mathrm{V}(\mathrm{II}) / \mathrm{V}(\mathrm{III})$ redox reactions by various electrochemical methods," Journal of Power Sources, vol. 139, no. 1-2, pp. 321-324, 2005.

[10] T. Sukkar and M. Skyllas-Kazacos, "Membrane stability studies for vanadium redox cell applications," Journal of Applied Electrochemistry, vol. 34, no. 2, pp. 137-145, 2004.

[11] B. Tian, C. W. Yan, and F. H. Wang, "Proton conducting composite membrane from Daramic/Nafion for vanadium redox flow battery," Journal of Membrane Science, vol. 234, no. 1-2, pp. 51-54, 2004.

[12] T. D. Gierke, G. E. Munn, and F. C. Wilson, “The morphology in nafion perfluorinated membrane products, as determined by wide- and small-angle x-ray studies," Journal of Polymer Science, vol. 19, no. 11, pp. 1687-1704, 1981.

[13] S. Eckroad, "Vanadium redox flow batteries: an in-depth analysis,” Tech. Rep. EPRI-1014836, Electric Power Research Institute, 2007.

[14] Z. S. Mai, H. M. Zhang, X. F. Li, C. Bi, and H. Dai, "Sulfonated poly(tetramethydiphenyl ether ether ketone) membranes for vanadium redox flow battery application," Journal of Power Sources, vol. 196, no. 1, pp. 482-487, 2011.

[15] D. Y. Chen, S. J. Wang, M. Xiao, and Y. Z. Meng, "Preparation and properties of sulfonated poly(fluorenyl ether ketone) membrane for vanadium redox flow battery application," Journal of Power Sources, vol. 195, no. 7, pp. 2089-2095, 2010.

[16] D. Y. Chen, S. J. Wang, M. Xiao, and Y. Z. Meng, "Synthesis and properties of novel sulfonated poly(arylene ether sulfone) ionomers for vanadium redox flow battery," Energy Conversion and Management, vol. 51, no. 12, pp. 2816-2824, 2010.

[17] L. Semiz, N. Demirci Sankir, and M. Sankir, "Influence of the basic membrane properties of the disulfonated poly(arylene ether sulfone) copolymer membranes on the vanadium redox flow battery performance," Journal of Membrane Science, vol. 468, pp. 209-215, 2014.

[18] L. Semiz, N. D. Sankir, and M. Sankir, "Directly copolymerized disulfonated poly(arylene ether sulfone) membranes for vanadium redox flow batteries," International Journal of Electrochemical Science, vol. 9, no. 6, pp. 3060-3067, 2014.
[19] M. Z. Yue, Y. P. Zhang, and Y. Chen, "Preparation and properties of sulfonated polyimide proton conductive membrane for vanadium redox flow battery," Advanced Materials Research, vol. 239-242, pp. 2779-2784, 2011.

[20] B. Zhang, S. Zhang, D. Xing, R. Han, C. Yin, and X. Jian, "Quaternized poly(phthalazinone ether ketone ketone) anion exchange membrane with low permeability of vanadium ions for vanadium redox flow battery application," Journal of Power Sources, vol. 217, pp. 296-302, 2012.

[21] S. Zhang, B. Zhang, D. Xing, and X. Jian, "Poly(phthalazinone ether ketone ketone) anion exchange membranes with pyridinium as ion exchange groups for vanadium redox flow battery applications," Journal of Materials Chemistry A, vol. 1, no. 39, pp. 12246-12254, 2013.

[22] X. Ling, C. Jia, J. Liu, and C. Yan, "Preparation and characterization of sulfonated poly(ether sulfone)/sulfonated poly(ether ether ketone) blend membrane for vanadium redox flow battery," Journal of Membrane Science, vol. 415-416, pp. 306-312, 2012.

[23] S. Liu, L. H. Wang, Y. Ding, B. Q. Liu, X. T. Han, and Y. L. Song, "Novel sulfonated poly (ether ether keton)/polyetherimide acid-base blend membranes for vanadium redox flow battery applications," Electrochimica Acta, vol. 130, pp. 90-96, 2014.

[24] S. Winardi, S. C. Raghu, M. O. Oo et al., "Sulfonated poly (ether ether ketone)-based proton exchange membranes for vanadium redox battery applications," Journal of Membrane Science, vol. 450, pp. 313-322, 2014.

[25] Z. Yuan, X. Li, J. Hu, W. Xu, J. Cao, and H. Zhang, "Degradation mechanism of sulfonated poly(ether ether ketone) (SPEEK) ion exchange membranes under vanadium flow battery medium," Physical Chemistry Chemical Physics, vol. 16, no. 37, pp. 1984119847, 2014.

[26] D. Chen and M. A. Hickner, " $\mathrm{V}^{5+}$ degradation of sulfonated Radel membranes for vanadium redox flow batteries," Physical Chemistry Chemical Physics, vol. 15, no. 27, pp. 11299-11305, 2013.

[27] B. Schwenzer, J. L. Zhang, S. W. Kim, L. Li, J. Liu, and Z. Yang, "Membrane development for vanadium redox flow batteries," ChemSusChem, vol. 4, no. 10, pp. 1388-1406, 2011.

[28] Y. Zhang, J. Li, L. Wang, and S. Zhang, "Sulfonated polyimide/AlOOH composite membranes with decreased vanadium permeability and increased stability for vanadium redox flow battery," Journal of Solid State Electrochemistry, vol. 18, no. 12, pp. 3479-3490, 2014.

[29] K. J. Lee and Y. H. Chu, "Preparation of the graphene oxide (GO)/Nafion composite membrane for the vanadium redox flow battery (VRB) system," Vacuum, vol. 107, pp. 269-276, 2014.

[30] L. Wu, Z. Zhang, J. Ran, D. Zhou, C. Li, and T. Xu, "Advances in proton-exchange membranes for fuel cells: An overview on proton conductive channels (PCCs)," Physical Chemistry Chemical Physics, vol. 15, no. 14, pp. 4870-4887, 2013.

[31] J. Xi, Z. Wu, X. Qiu, and L. Chen, "Nafion $/ \mathrm{SiO}_{2}$ hybrid membrane for vanadium redox flow battery," Journal of Power Sources, vol. 166, no. 2, pp. 531-536, 2007.

[32] X. Teng, Y. Zhao, J. Xi, Z. Wu, X. Qiu, and L. Chen, "Nafion/organic silica modified $\mathrm{TiO}_{2}$ composite membrane for vanadium redox flow battery via in situ sol-gel reactions," Journal of Membrane Science, vol. 341, no. 1-2, pp. 149-154, 2009.

[33] N. Wang, S. Peng, D. Lu, S. Liu, Y. Liu, and K. Huang, "Nafion/ $\mathrm{TiO}_{2}$ hybrid membrane fabricated via hydrothermal method for vanadium redox battery," Journal of Solid State Electrochemistry, vol. 16, no. 4, pp. 1577-1584, 2012. 
[34] S. Sang, Q. Wu, and K. Huang, "Preparation of zirconium phosphate (ZrP)/Nafion1135 composite membrane and $\mathrm{H}^{+} / \mathrm{VO}^{2}+$ transfer property investigation," Journal of Membrane Science, vol. 305, no. 1-2, pp. 118-124, 2007.

[35] D. Schulte, J. Drillkens, B. Schulte, and D. U. Sauer, "Nafion hybrid membranes for use in redox flow batteries," Journal of the Electrochemical Society, vol. 157, no. 9, pp. A989-A992, 2010.

[36] Z. Li, W. Dai, L. Yu et al., "Properties investigation of sulfonated poly(ether ether ketone)/polyacrylonitrile acid-base blend membrane for vanadium redox flow battery application," ACS Applied Materials \& Interfaces, vol. 6, no. 21, pp. 1888518893, 2014

[37] W. Dai, Y. Shen, Z. Li, L. Yu, J. Xi, and X. Qiu, "SPEEK/Graphene oxide nanocomposite membranes with superior cyclability for highly efficient vanadium redox flow battery," Journal of Materials Chemistry A, vol. 2, no. 31, pp. 12423-12432, 2014.

[38] N. Wang, S. Peng, H. Wang, Y. Li, S. Liu, and Y. Liu, "SPPEK $/ \mathrm{WO}_{3}$ hybrid membrane fabricated via hydrothermal method for vanadium redox flow battery," Electrochemistry Communications, vol. 17, no. 1, pp. 30-33, 2012.

[39] N. Wang, J. Yu, Z. Zhou, D. Fang, S. Liu, and Y. Liu, "SPPEK/TPA composite membrane as a separator of vanadium redox flow battery," Journal of Membrane Science, vol. 437, pp. 114-121, 2013.

[40] Y. Zhang, J. Li, H. Zhang, S. Zhang, and X. Huang, "Sulfonated polyimide membranes with different non-sulfonated diamines for vanadium redox battery applications," Electrochimica Acta, vol. 150, pp. 114-122, 2014.

[41] D. Chen, M. A. Hickner, S. Wang, J. Pan, M. Xiao, and Y. Meng, "Directly fluorinated polyaromatic composite membranes for vanadium redox flow batteries," Journal of Membrane Science, vol. 415-416, pp. 139-144, 2012.

[42] J. Pan, S. Wang, M. Xiao, M. Hickner, and Y. Meng, "Layered zirconium phosphate sulfophenylphosphonates reinforced sulfonated poly (fluorenyl ether ketone) hybrid membranes with high proton conductivity and low vanadium ion permeability," Journal of Membrane Science, vol. 443, pp. 19-27, 2013.

[43] J. Li, Y. Zhang, and L. Wang, "Preparation and characterization of sulfonated polyimide $/ \mathrm{TiO}_{2}$ composite membrane for vanadium redox flow battery," Journal of Solid State Electrochemistry, vol. 18, no. 3, pp. 729-737, 2014.

[44] J. Li, Y. Zhang, S. Zhang, X. Huang, and L. Wang, "Novel sulfonated polyimide $/ \mathrm{ZrO}_{2}$ composite membrane as a separator of vanadium redox flow battery," Polymers for Advanced Technologies, vol. 25, no. 12, pp. 1610-1615, 2014.

[45] J. Qiu, J. Zhang, J. Chen et al., "Amphoteric ion exchange membrane synthesized by radiation-induced graft copolymerization of styrene and dimethylaminoethyl methacrylate into PVDF film for vanadium redox flow battery applications," Journal of Membrane Science, vol. 334, no. 1-2, pp. 9-15, 2009.

[46] J. Qiu, M. Zhai, J. Chen et al., "Performance of vanadium redox flow battery with a novel amphoteric ion exchange membrane synthesized by two-step grafting method," Journal of Membrane Science, vol. 342, no. 1-2, pp. 215-220, 2009.

[47] J. Yuan, C. Yu, J. Peng et al., "Facile synthesis of amphoteric ion exchange membrane by radiation grafting of sodium styrene sulfonate and $\mathrm{N}, \mathrm{N}$-dimethylaminoethyl methacrylate for vanadium redox flow battery," Journal of Polymer Science, Part A: Polymer Chemistry, vol. 51, no. 24, pp. 5194-5202, 2013.

[48] G. Hu, Y. Wang, J. Ma et al., "A novel amphoteric ion exchange membrane synthesized by radiation-induced grafting $\alpha$-methylstyrene and $N, N$-dimethylaminoethyl methacrylate for vanadium redox flow battery application," Journal of Membrane Science, vol. 407-408, pp. 184-192, 2012.

[49] Y. Wang, S. Wang, M. Xiao et al., "Amphoteric ion exchange membrane synthesized by direct polymerization for vanadium redox flow battery application," International Journal of Hydrogen Energy, vol. 39, no. 28, pp. 16123-16131, 2014.

[50] H. Zhang, H. Zhang, X. Li, Z. Mai, and J. Zhang, "Nanofiltration (NF) membranes: the next generation separators for all vanadium redox flow batteries (VRBs)?” Energy \& Environmental Science, vol. 4, no. 5, pp. 1676-1679, 2011.

[51] H. Zhang, H. Zhang, X. Li, Z. Mai, and W. Wei, "Silica modified nanofiltration membranes with improved selectivity for redox flow battery application," Energy \& Environmental Science, vol. 5, no. 4, pp. 6299-6303, 2012.

[52] H. Zhang, H. Zhang, F. Zhang, X. Li, Y. Li, and I. Vankelecom, "Advanced charged membranes with highly symmetric spongy structures for vanadium flow battery application," Energy \& Environmental Science, vol. 6, no. 3, pp. 776-781, 2013.

[53] X. Wei, Z. Nie, Q. Luo, B. Li, V. Sprenkle, and W. Wang, "Polyvinyl chloride/silica nanoporous composite separator for all-vanadium redox flow battery applications," Journal of the Electrochemical Society, vol. 160, no. 8, pp. A1215-A1218, 2013.

[54] X. Wei, Z. Nie, Q. Luo et al., "Nanoporous polytetrafluoroethylene/silica composite separator as a high-performance all-vanadium redox flowbattery membrane," Advanced Energy Materials, vol. 3, no. 9, pp. 1215-1220, 2013.

[55] R. Yang, Z. Xu, S. Yang et al., "Nonionic zeolite membrane as potential ion separator in redox-flow battery," Journal of Membrane Science, vol. 450, pp. 12-17, 2014.

[56] Z. Xu, I. Michos, X. Wang, R. Yang, X. Gu, and J. Dong, "A zeolite ion exchange membrane for redox flow batteries," Chemical Communications, vol. 50, no. 19, pp. 2416-2419, 2014.

[57] H. Tang, Z. Wan, M. Pan, and S. P. Jiang, "Self-assembled Nafion-silica nanoparticles for elevated-high temperature polymer electrolyte membrane fuel cells," Electrochemistry Communications, vol. 9, no. 8, pp. 2003-2008, 2007.

[58] Z.-G. Shao, H. Xu, M. Q. Li, and I.-M. Hsing, "Hybrid Nafioninorganic oxides membrane doped with heteropolyacids for high temperature operation of proton exchange membrane fuel cell," Solid State Ionics, vol. 177, no. 7-8, pp. 779-785, 2006.

[59] T. Jian-hua, G. Peng-fei, Z. Zhi-yuan, L. Wen-hui, and S. Zhongqiang, "Preparation and performance evaluation of a Nafion$\mathrm{TiO}_{2}$ composite membrane for PEMFCs," International Journal of Hydrogen Energy, vol. 33, no. 20, pp. 5686-5690, 2008.

[60] E. B. Easton, B. L. Langsdorf, J. A. Hughes et al., "Characteristics of polypyrrole/nafion composite membranes in a direct methanol fuel cell," Journal of the Electrochemical Society, vol. 150, no. 10, pp. C735-C739, 2003.

[61] C. Yang, S. Srinivasan, A. S. Aricò, P. Cretì, V. Baglio, and V. Antonucci, "Composite Nafion/zirconium phosphate membranes for direct methanol fuel cell operation at high temperature," Electrochemical \& Solid-State Letters, vol. 4, no. 4, pp. A31A34, 2001.

[62] V. Baglio, A. S. Aricò, A. D. Blasi et al., "Nafion- $-\mathrm{TiO}_{2}$ composite DMFC membranes: physico-chemical properties of the filler versus electrochemical performance," Electrochimica Acta, vol. 50, no. 5, pp. 1241-1246, 2005.

[63] K. A. Mauritz and R. M. Warren, "Microstructural evolution of a silicon oxide phase in a perfluorosulfonic acid ionomer by an in situ sol-gel reaction. 1. Infrared spectroscopic studies," Macromolecules, vol. 22, no. 5, pp. 1730-1734, 1989. 
[64] K. A. Mauritz and I. D. Stefanithis, "Microstructural evolution of a silicon oxide phase in a perfluorosulfonic acid ionomer by an in situ sol-gel reaction. 2. Dielectric relaxation studies," Macromolecules, vol. 23, no. 5, pp. 1380-1388, 1990.

[65] K. A. Mauritz, I. D. Stefanithis, S. V. Davis et al., "Microstructural evolution of a silicon oxide phase in a perfluorosulfonic acid ionomer by an in situ sol-gel reaction," Journal of Applied Polymer Science, vol. 55, no. 1, pp. 181-190, 1995.

[66] Q. Luo, H. Zhang, J. Chen, D. You, C. X. Sun, and Y. Zhang, "Preparation and characterization of Nafion/SPEEK layered composite membrane and its application in vanadium redox flow battery," Journal of Membrane Science, vol. 325, no. 2, pp. 553-558, 2008.

[67] N. Miyake, J. S. Wainright, and R. F. Savinell, "Evaluation of a sol-gel derived nafion/silica hybrid membrane for polymer electrolyte membrane fuel cell applications: II. methanol uptake and methanol permeability," Journal of the Electrochemical Society, vol. 148, no. 8, pp. A905-A909, 2001.

[68] X. Teng, J. Dai, J. Su, Y. Zhu, H. Liu, and Z. Song, "A high performance polytetrafluoroethene/Nafion composite membrane for vanadium redox flow battery application," Journal of Power Sources, vol. 240, pp. 131-139, 2013.

[69] J. Kim, J.-D. Jeon, and S.-Y. Kwak, "Nafion-based composite membrane with a permselective layered silicate layer for vanadium redox flow battery," Electrochemistry Communications, vol. 38, pp. 68-70, 2014.

[70] Z. Li, W. Dai, L. Yu, J. Xi, X. Qiu, and L. Chen, "Sulfonated poly(ether ether ketone)/mesoporous silica hybrid membrane for high performance vanadium redox flow battery," Journal of Power Sources, vol. 257, no. 1, pp. 221-229, 2014.

[71] M. Vijayakumar, B. Schwenzer, S. Kim et al., "Investigation of local environments in Nafion- $\mathrm{SiO}_{2}$ composite membranes used in vanadium redox flow batteries," Solid State Nuclear Magnetic Resonance, vol. 42, pp. 71-80, 2012.

[72] Z. Mai, H. Zhang, X. Li, S. Xiao, and H. Zhang, "Nafion/ polyvinylidene fluoride blend membranes with improved ion selectivity for vanadium redox flow battery application," Journal of Power Sources, vol. 196, no. 13, pp. 5737-5741, 2011.

[73] Y. G. Shul and Y. H. Chu, "Nafion/graphene oxide layered structure membrane for the vanadium redox flow battery," Science of Advanced Materials, vol. 6, no. 7, pp. 1445-1452, 2014.

[74] R. Yang, Z. Cao, S. Yang, I. Michos, Z. Xu, and J. H. Dong, "Colloidal silicalite-nafion composite ion exchange membrane for vanadium redox-flow battery," Journal of Membrane Science, vol. 484, pp. 1-9, 2015.

[75] P. K. Leung, Q. Xu, T. S. Zhao, L. Zeng, and C. Zhang, "Preparation of silica nanocomposite anion-exchange membranes with low vanadium-ion crossover for vanadium redox flow batteries," Electrochimica Acta, vol. 105, pp. 584-592, 2013.

[76] C. H. Rhee, H. K. Kim, H. Chang, and J. S. Lee, "Nafion/ sulfonated montmorillonite composite: a new concept electrolyte membrane for direct methanol fuel cells," Chemistry of Materials, vol. 17, no. 7, pp. 1691-1697, 2005.

[77] N. Miyake, J. S. Wainright, and R. F. Savinell, "Evaluation of a sol-gel derived nafion/silica hybrid membrane for proton electrolyte membrane fuel cell applications: I. Proton conductivity and water content," Journal of the Electrochemical Society, vol. 148, no. 8, pp. A898-A904, 2001.

[78] C. H. Lin, M. C. Yang, and H. J. Wei, "Amino-silica modified Nafion membrane for vanadium redox flow battery," Journal of Power Sources, vol. 282, pp. 562-571, 2015.
[79] L. Cao, Q. Q. Sun, Y. H. Gao, L. T. Liu, and H. F. Shi, "Novel acidbase hybrid membrane based on amine-functionalized reduced graphene oxide and sulfonated polyimide for vanadium redox flow battery," Electrochimica Acta, vol. 158, pp. 24-34, 2015.

[80] Y. Heo, H. Im, and J. Kim, "The effect of sulfonated graphene oxide on sulfonated poly(ether ether ketone) membrane for direct methanol fuel cells," Journal of Membrane Science, vol. 425-426, pp. 11-22, 2013.

[81] J. Li, Y. Zhang, S. Zhang, and X. Huang, "Sulfonated polyimide/ $\mathrm{s}-\mathrm{MoS}_{2}$ composite membrane with high proton selectivity and good stability for vanadium redox flow battery," Journal of Membrane Science, vol. 490, pp. 179-189, 2015. 

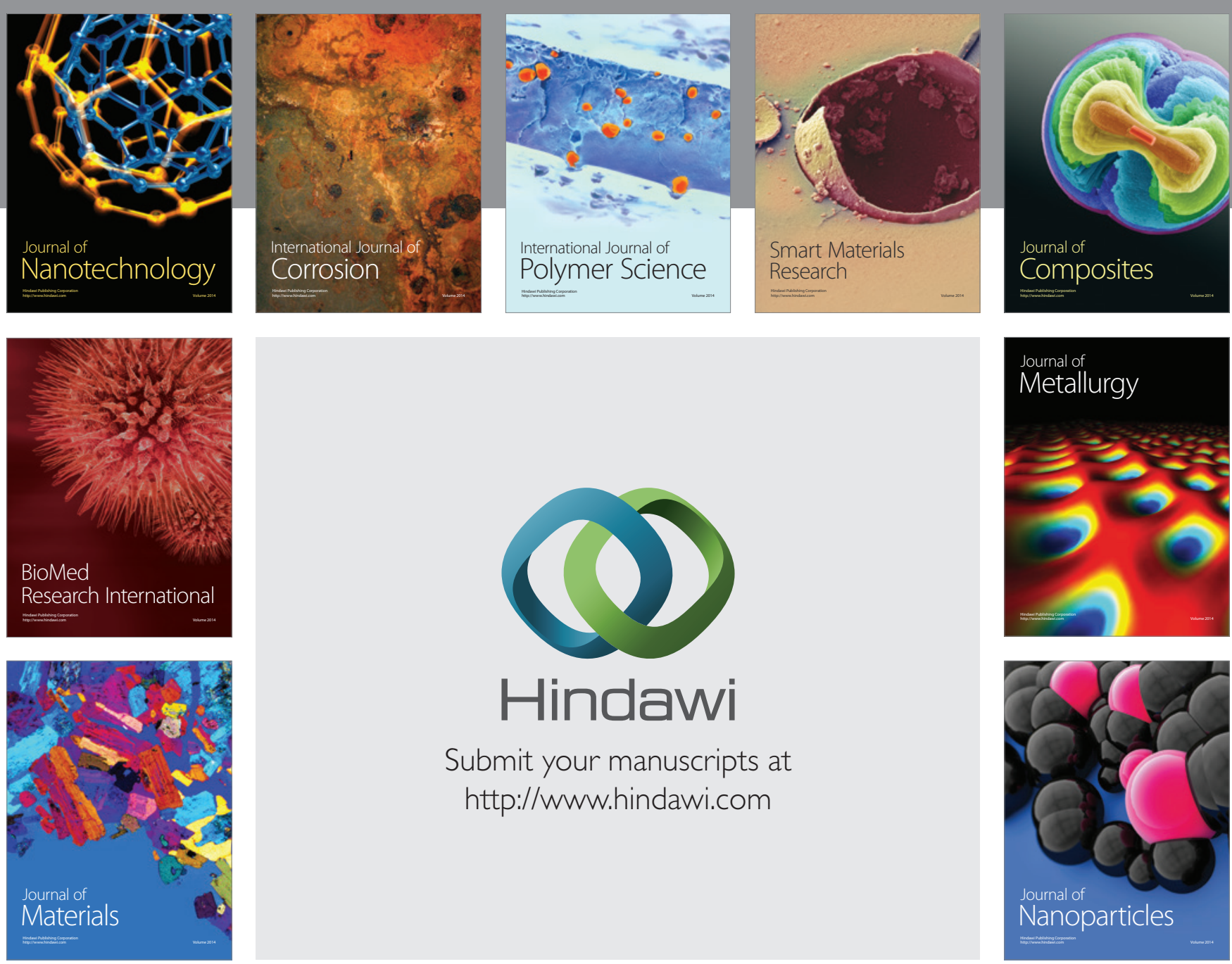

Submit your manuscripts at http://www.hindawi.com
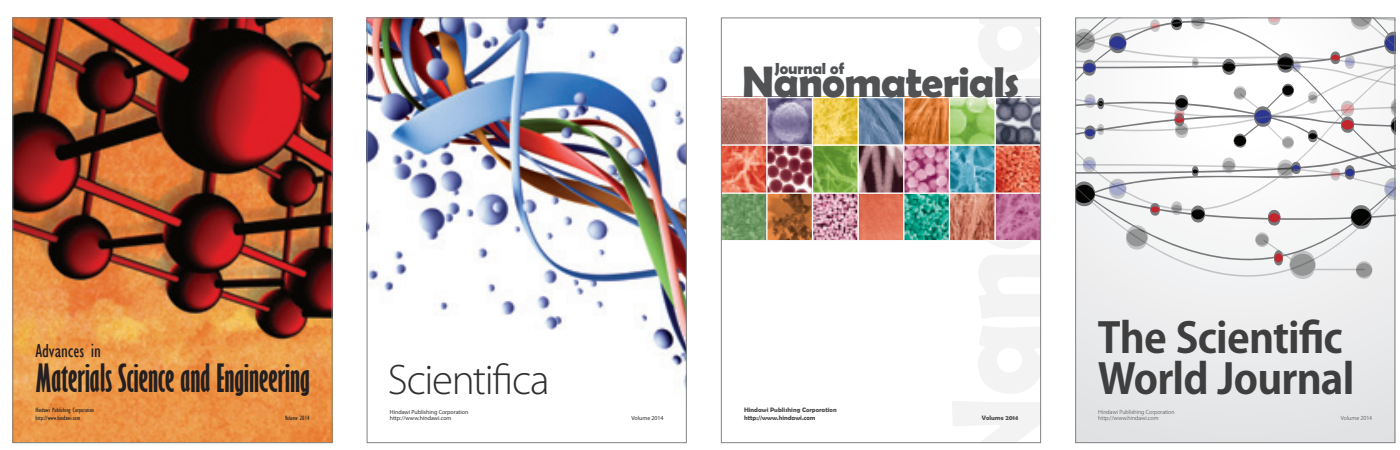

\section{The Scientific World Journal}
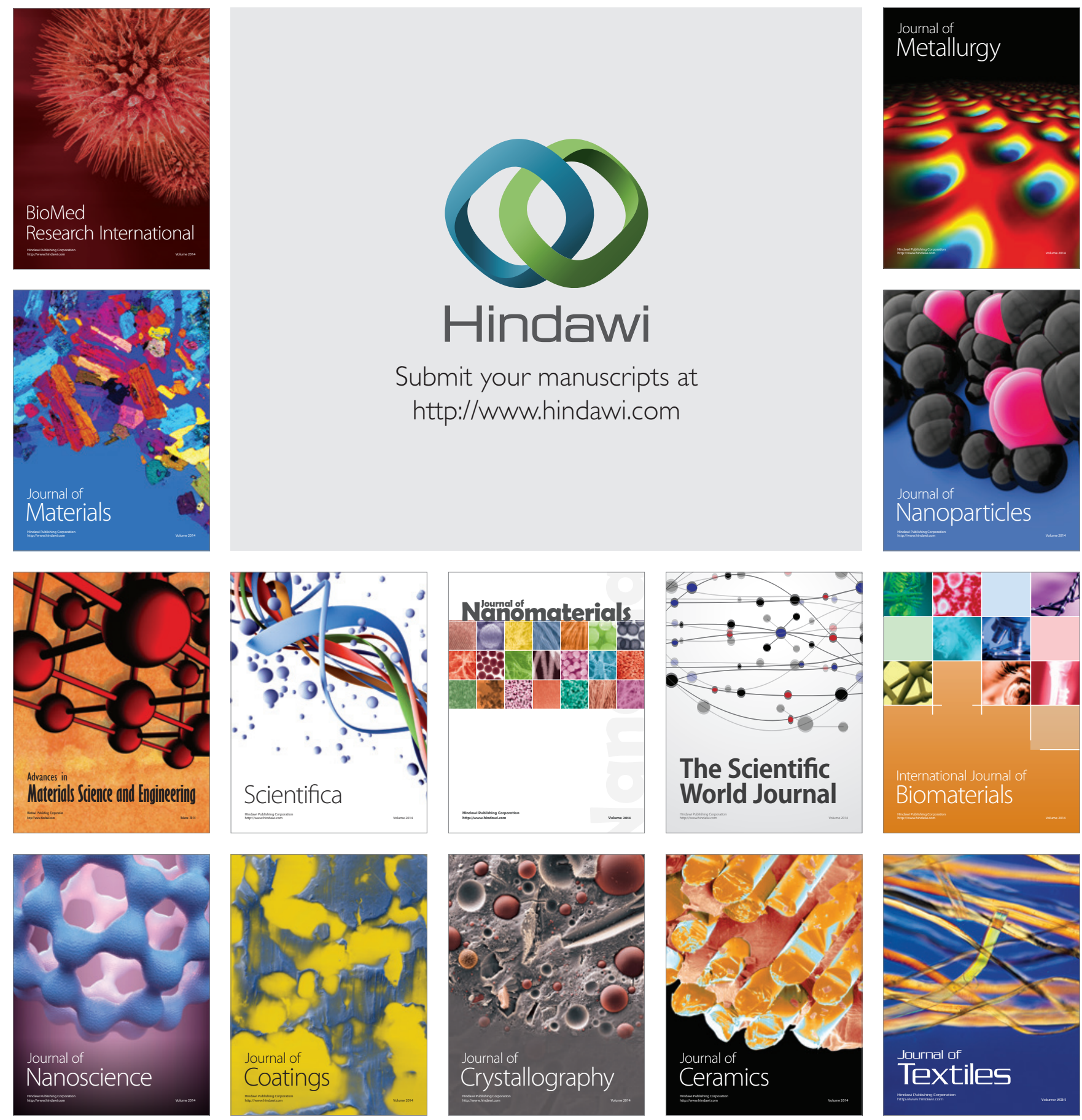